\title{
The Role of Performance Materials in a Federal Materials Initiative
}

\author{
Mary L. Good
}

Under the rubric of "competitiveness" and "global markets," policymakers in the United States have begun to debate what the nation should do to support our industrial base, protect our workforce, and maintain our standard of living. The concept of the creation and execution of a national "industrial policy" is not attractive in the context of free markets, industrial competition, and limited government interference in private enterprise. However, there is a building consensus that our long-term commitment to federally funded basic research should include the support of generic technologies which will be the basis of competitive products in the years ahead.

This momentum has resulted in a series of assessments of "critical technologies," first from the Department of Defense, then from the Department of Commerce, and now from the Office of Science and Technology Policy (OSTP) in the form of the Critical Technologies Report. These reports all attempt to assess emerging and underlying technologies which will be the drivers in the next generation of products and services. They also try to benchmark the United States' position in these technologies vis-a-vis our international competitors, particularly in Europe and Japan.

The reports have many things in common, but one persistent theme stands out. In every case, materials technology, partic- ularly that related to advanced performance materials, is highlighted as a critical fundamental area where advancements will control future developments. The critical materials technologies include metals,

\section{The enabling technology in many high tech products is a performance material.}

ceramics, polymers, composites, and electronics, superconducting, magnetic, optical, and biological materials. In what can be considered as a first step toward a national technology policy, this awareness of the importance of materials technology has encouraged a "federal materials initiative." D. Allan Bromley, in his role as chair of the Federal Coordinating Council for Science, Engineering, and Technology (FCCSET), has initiated a Steering Group on Materials under the Committee on Industry and Technology. Their charter is to maximize the value of federal programs in materials, to identify policy issues, and to provide a data base on federal materials programs.
The intent is to monitor programs from basic research to development, improve materials standards, improve technology transfer to the private sector, and encourage government-industry-university partnerships in materials research and development. Particular emphasis will be placed on materials synthesis and processing, and a new NSF initiative will be funded for fiscal year 1992.

I believe this national emphasis is timely and well positioned to enhance our potential for international competitiveness. As we look at the high tech products (and the not so high tech) today, the enabling technology in many of them is a performance material. Improved efficiency and pollution control in aircraft and automotive engines require new thermally stable, durable materials to allow high temperature operations. Next-generation electronic substrates require materials capable of nanometer processing. If hightemperature superconductors are to fulfill their promise, new processing technologies must be found to allow for high currents in bulk materials. Many other such examples abound.

However, for these initiatives to succeed, the scientific and engineering communities in government, universities, and industry must respond. We must find ways to produce these materials in an economically competitive manner. We must couple the basic research output to innovation for new products. We capture the value of the materials research as rapidly as possible and reduce the cycle time between a research finding and a commercial offering. The burden is on the technical community to work together to make that happen. The government is taking the risk to sponsor the research-we must accept the responsibility to make it valuable in our open, free market system.

Mary L. Good is Senior Vice President for Technology at Allied-Signal, Inc., Morristown, New Jersey. She also chairs the National Science Board. 


\section{Others will}

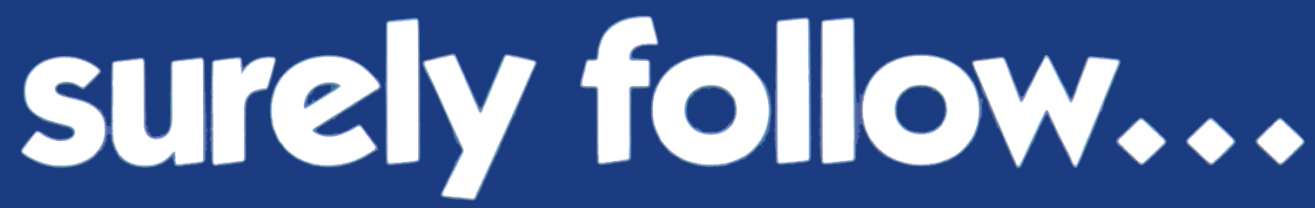

Three years ago, Princeton Gamma-Tech developed and introduced the first workstation-based microanalyzer for advanced $X$-ray and image analysis in the field of electron and light microscopy. Some have followed our lead. Others surely will.

We're not surprised. For 25 years, PGT's breakthroughs and innovations in the commercial development of energy dispersive spectroscopy have been a constant. Here are the latest and best you should know more about:

IMIX '“- PGT's IMIX System is designed to aid the microscopist with advanced $X$-ray and image analysis. It utilizes a SUN SPARCstation ${ }^{\text {"w }}$ workstation for true multiuser/multitasking capability - with 32-bit architecture for superior processing power and speed. A click of the mouse starts X-ray collection or a complete analysis. Unsurpassed workstation graphics capabilities permit display of images, graphs and analytical data - all on a single screen.

Powerful PGT processing and analysis software extracts all the information locked within your samples. And analysis of nonideal samples is handled automatically with unique artificial intelligence-based programs. It's a remarkable system. One that increases throughput and lab productivity through automation and simplicity of operation.

IMAGIST ${ }^{\text {'M }}$ is another PGT leading-edge workstation system, designed for light microscopy and electron column-based image processing and analysis. Also SUN SPARCstation ${ }^{\text {'M }}$ based, it's an afford- able and totally complete package for automation, acquisition, image processing, analysis and presentation. Microscopists can quickly collect images, easily extract features and data from samples, process and analyze them - and then present results.

SUPPORT - Technical support at PGT means applications support, professional user school training, day-to-day technical assistance or 24-hour service support. Each is readily available to you worldwide - not just in words but in deeds. Ours is an unusually strong technical support orientation; we've been perfecting it for 25 years.

PGT - Leader from the beginning, committed to stay in front.

Please visit Booth No. 910-911 at the MRS Show in Boston, December 3-5, 1991.
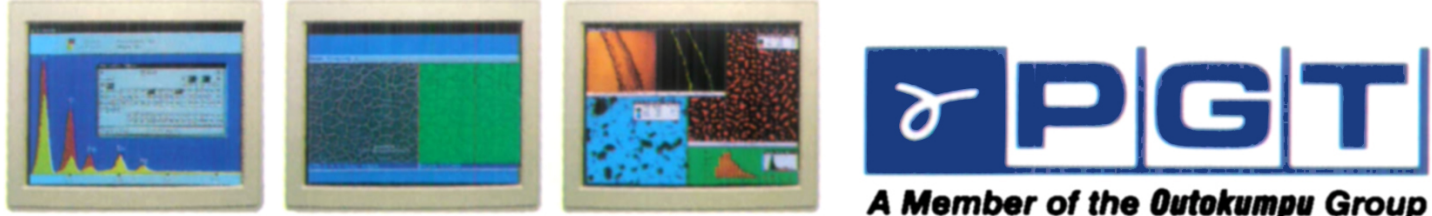

A Member of the Outokumpu Group

PRINCETON GAMMA-TECH, INC., 1200 State Road, Princeton, NJ 08540 Tel: 609-924-7310 Fax: 609-924-1729 PGT, UK, Business \& Technical Center, \#2-4 Mancetter Square, Warington,

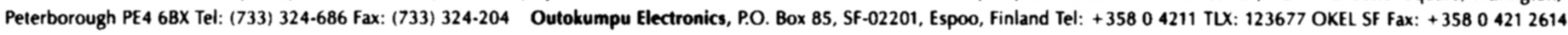

